\title{
Platelet-Neutrophil Interactions Are Lower in Cord Blood of Premature Newborns
}

\author{
Ijeoma Esiaba ${ }^{a}$ Danilyn M. Angeles ${ }^{b}$ Terry-Ann M. Milford ${ }^{c}$ Lorena M. Salto ${ }^{d}$ \\ Kimberly J. Paynec Melissa Y. Kiddere Danilo S. Boskovic ${ }^{a, f}$ \\ ${ }^{a}$ Department of Earth and Biological Sciences, School of Medicine, Loma Linda University, Loma Linda, CA, USA; \\ ${ }^{b}$ Division of Physiology, Department of Basic Sciences, School of Medicine, Loma Linda University, Loma Linda, \\ CA, USA; ' Division of Anatomy, Department of Pathology and Human Anatomy, School of Medicine, Loma Linda

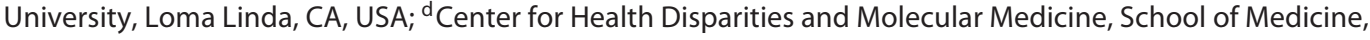 \\ Loma Linda University, Loma Linda, CA, USA; ' Department of Obstetrics and Gynecology, School of Medicine, \\ Loma Linda University, Loma Linda, CA, USA; ${ }^{\mathrm{D}}$ Division of Biochemistry, Department of Basic Sciences, School of \\ Medicine, Loma Linda University, Loma Linda, CA, USA
}

\section{Keywords}

Platelet activation - Platelet function - Neutrophil function · Platelet-neutrophil interaction · Platelet · Neutrophil ·

Prematurity

\begin{abstract}
Objective: To quantify platelet-neutrophil interaction by flow cytometry, in newborn cord blood, as a function of gestational age. Rationale: Little is known about platelet function markers in the newborn, and developmental variations in these markers are not well described. Methods: Cord blood samples were obtained from 64 newborns between 23 and 40 weeks' gestation. The neonates were grouped into three categories: preterm ( $<34$ weeks' gestation, $n=21$ ), late preterm (34 to $<37$ weeks' gestation, $n=22$ ), and term ( $\geq 37$ weeks' gestation, $n=21$ ). We monitored the expression of P-selectin and the formation of platelet-neutrophil aggregates (PNAs) by flow cytometry while using adenosine $5^{\prime}$-diphosphate (ADP) or thrombin receptor-activating peptide
\end{abstract}

\section{KARGER}

(c) 2018 S. Karger AG, Basel

E-Mail karger@karger.com

www.karger.com/neo
(TRAP) as agonists. Results: PNAs were significantly lower in preterm compared to term neonates after TRAP or ADP stimulations $(11.5 \pm 5.2 \%$ vs. $19.9 \pm 9.1 \%, p<0.001$, or $24.0 \pm$ $10.1 \%$ vs. $39.1 \pm 18.2 \%, p=0.008$, respectively). The expression of P-selectin also tended to be lower in preterm neonates, with significant positive correlations between $\mathrm{P}$-selectin expression and PNA formation. Conclusions: The potential formation of PNAs correlates with gestational age. This suggests that the development of functional competencies of platelets and neutrophils continues throughout gestation, progressively enabling interactions between them.

(c) 2018 S. Karger AG, Basel

\section{Introduction}

Platelets were first described in 1865 by Max Schultze [1]. Apart from their role in thrombus formation [2], platelets are now known to be involved in inflammation [3], angiogenesis [4], tissue repair and wound healing [5, 
$6]$, immunity $[7,8]$, and even cancer growth $[9,10]$. In spite of these advances in platelet study, much remains to be learned about the developmental aspects of fetal and neonatal platelet function [11].

Previous platelet studies in the newborn tended to focus on clotting and bleeding times or platelet counts [12]. Such studies highlighted the increased risk of bleeding associated with thrombocytopenia in the newborn [12, 13]. Hemorrhagic morbidities such as intraventricular hemorrhage as well as pulmonary and gastrointestinal bleeding increase the risk of mortality especially in preterm newborns $[14,15]$. However, many newborns who develop hemorrhagic disorders are not thrombocytopenic [16]. This implies that endogenously produced circulating platelets may not adequately provide the needed hemostatic support [17]. Therefore, neonatal platelet function studies are needed to further characterize the etiology and pathophysiology of these morbidities.

Neonatal platelets are said to be hyporesponsive to stimulation when compared to adult platelets [18-20]. However, they appear to adequately protect the healthy newborn. Cord and peripheral blood samples from neonates were reported to have shorter clot formation times [21] and platelet function analyzer-100 closure times (a measure of platelet adhesion and aggregation functions) [22]. Nevertheless, the coagulation system is increasingly impaired the earlier the gestation [23], and preterm neonates may not be fully protected.

A number of receptor- and agonist-specific responses were documented $[19,24]$, suggesting that all aspects of newborn platelet function are not necessarily hyporesponsive. As such, P-selectin is a well-studied marker of platelet activation in both adults and newborns. However, the expression of this a-granule component may be lower in newborns $[24,25]$. It is expressed on the platelet surface after activation and serves as a receptor for binding to leukocytes and endothelial cells $[26,27]$. The formation of platelet-neutrophil aggregates (PNAs), however, was not explored in neonates, even though recent studies in adults and animal models highlight such interactions $[28,29]$. Neutrophil functions, such as a respiratory burst, transcellular production of eicosanoids, chemotaxis, extravasation into tissues and sites of infection, phagocytosis, and NETosis are enhanced upon interaction with platelets [30].

The developmental aspects of neonatal platelet activation and function still remain to be fully characterized. In this study, we compared the expression of P-selectin as a marker of platelet activation and the subsequent interaction of platelets with neutrophils in cord blood samples at different gestational ages. We hypothesized that these markers of platelet activation and function would be lower in preterm compared to term newborns. This information may be helpful in evaluating the risk assessment of some bleeding morbidities, especially those associated with prematurity.

\section{Methods}

\section{Subject and Sample Collection}

Approval for the study was obtained from the Loma Linda University Health Institutional Review Board prior to subject recruitment. Consent for the study was obtained from the mothers of neonates born at the Loma Linda University Children's Hospital labor and delivery unit. Newborns with congenital disorders were excluded. Maternal and infant medical records were reviewed for subject characteristics such as age of the mother, gestational age and birthweight of the neonate, mode of delivery, sex, and Apgar scores at 1 and $5 \mathrm{~min}$. Cord blood samples were drawn from double-clamped umbilical cords into $2.7-\mathrm{mL} 3.2 \%$ trisodium citrate Vacuette tubes (Greiner Bio-One) using a 21-gauge needle.

\section{Flow Cytometry Analysis}

Within 30 min of blood sampling, aliquots of whole blood were incubated at room temperature with fluorescently labelled monoclonal antibodies and either $20 \mu \mathrm{M}$ adenosine $5^{\prime}$-diphosphate (ADP; Sigma-Aldrich), $20 \mu \mathrm{M}$ thrombin receptor-activating peptide (TRAP; Ser-Phe-Leu-Leu-Arg-Asn-Pro-Asn-Asp-Lys-TyrGlu-Pro-Phe, Sigma-Aldrich) or HEPES-Tyrode buffer $(10 \mathrm{mM}$ HEPES, $137 \mathrm{mM} \mathrm{NaCl}, 2.8 \mathrm{mM} \mathrm{KCl}, 1 \mathrm{mM} \mathrm{MgCl}_{2}, 12 \mathrm{mM} \mathrm{NaHCO}_{3}$, $0.4 \mathrm{mM} \mathrm{Na}_{2} \mathrm{HPO}_{4}, 5.5 \mathrm{mM}$ glucose, $0.35 \% \mathrm{w} / \mathrm{v}$ bovine serum albumin, $\mathrm{pH}$ 7.4). Samples were further diluted with phosphate-buffered saline (PBS; pH 7.4) and then analyzed on the MACSQuant ${ }^{\circledR}$ Analyzer 10 (Miltenyi Biotec Inc.). All experiments were conducted in duplicates. The flow cytometer was calibrated daily to assure proper instrument functioning. Consistent fluorescence measurements over time were monitored with URFP-30-2 beads (Spherotech Inc.).

\section{P-Selectin Expression}

Platelet surface P-selectin expression was determined using whole-blood flow cytometry by the modified method of Psaila et al. [31] and Frelinger et al. [17]. The antibodies used were as follows: phycoerythrin (PE)-conjugated anti-P-selectin (antiCD62P) monoclonal antibody (clone AK4, $2 \mu \mathrm{g} / \mathrm{mL}$ final, Biolegend Inc.) and peridinin-chlorophyll-protein (PerCP)-conjugated anti-GPIIIa (anti-CD61) monoclonal antibody (clone VI-PL2, $2 \mu \mathrm{g} / \mathrm{mL}$ final, Biolegend Inc.). PE-conjugated mouse IgG $\mathrm{I}_{1}$ isotype (Biolegend Inc.) served as a negative control for P-selectin. Aliquots of whole blood $(5 \mu \mathrm{L})$ were incubated with $5 \mu \mathrm{L}$ fluorescently labeled monoclonal antibodies and $2.5 \mu \mathrm{L}$ of either ADP, TRAP, or HEPES-Tyrode buffer for $15 \mathrm{~min}$ at room temperature. The reaction was stopped by a 15 -fold dilution with $1 \%$ formaldehyde in PBS. Samples were maintained at room temperature and not agitated until fixation was completed to prevent handling activation. They were further diluted 35-fold with PBS and analyzed 

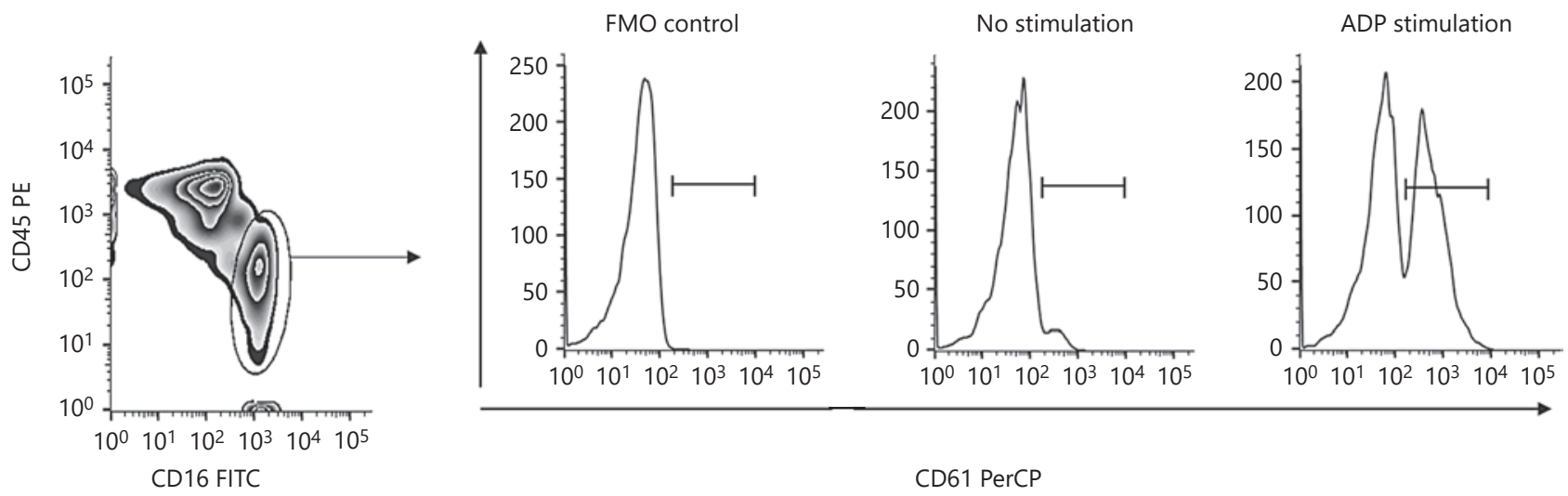

CD61 PerCP

Fig. 1. Gating for platelet-neutrophil aggregates (PNAs). In the scatter plot on the left, neutrophils were gated as the CD45LO and CD16+ double-positive cell population. The histograms on the right show the percentage of PNAs positive for CD61 without and with stimulation with ADP (right panel) or TRAP (data not shown). The left histogram shows the FMO control used to set gates for CD61 positivity. ADP, adenosine $5^{\prime}$-diphosphate; FITC, fluorescein isothiocyanate; FMO, fluorescence minus one; PE, phycoerythrin; PerCP, peridinin-chlorophyll-protein; TRAP, thrombin receptor-activating peptide. within 24 h. For each sample 10,000 CD61 PerCP-positive platelet events were acquired. Platelet surface P-selectin expression was measured relative to the negative control as percentage of CD62P PE-positive platelets.

\section{Platelet-Neutrophil Aggregates}

The method of Nagasawa et al. [32] was modified for analysis of PNAs. Whole blood samples $(5 \mu \mathrm{L})$ were incubated with $5 \mu \mathrm{L}$ antibodies and $2.5 \mu \mathrm{L}$ of either ADP, TRAP, or HEPES-Tyrode buffer for $10 \mathrm{~min}$ at room temperature $\left(25^{\circ} \mathrm{C}\right)$. The antibodies used were PE-conjugated anti-CD45 monoclonal antibody (clone HI30, Biolegend Inc., $8 \mu \mathrm{g} / \mathrm{mL}$ final; CD 45 is a pan-leukocyte protein), PerCP-conjugated anti-CD61 monoclonal antibody (clone VI-PL2, Biolegend Inc., $2 \mu \mathrm{g} / \mathrm{mL}$ final), and fluorescein isothiocyanate-anti-CD16 (Fc $\gamma$ RIII receptor) monoclonal antibody (clone NKP15, Beckton Dickinson, $4 \mu \mathrm{g} / \mathrm{mL}$ final). Samples were fixed with $1 \%$ formaldehyde for $10 \mathrm{~min}$ at $25^{\circ} \mathrm{C}$, followed by red blood cell lysis by hypotonic shock. The volume was made up to $250 \mu \mathrm{L}$ with PBS and analyzed by flow cytometry. Fluorescence trigger was set on the B2 (PE) channel.

CD45LO and CD16+ double-positive cells were gated as the neutrophil population after doublet discrimination. Fluorescence minus one isotype controls, without PerCP-conjugated anti-CD61 monoclonal antibody, served as a negative control. PNAs were identified as the percentages of CD61+ cells in the gated neutrophil populations and defined by fluorescence intensity exceeding that of $99 \%$ of fluorescence minus one control neutrophils (Fig. 1).

\section{Statistical Analysis}

The study population was grouped into three categories based on gestational age: preterm ( $<34$ weeks), late preterm ( 34 to $<37$ weeks), and term ( $\geq 37$ weeks). Data were analyzed for normality by the Kolmogorov-Smirnoff test and by boxplots, and data that did not follow a normal distribution were transformed logarithmically. Nonparametric data were analyzed by the Kruskal-Wallis test and reported as median with interquartile range. Categorical variables were examined using the $\chi^{2}$ test. Cord blood platelet markers and parametric study characteristics between the preterm, late preterm, and term neonatal groups were analyzed by one-way ANOVA followed by Bonferroni post hoc test comparisons. Pearson's correlation coefficient was used to assess the correlation between cord blood PNAs and P-selectin. We set the a level at $p<0.05$. Data were analyzed with the IBM SPSS for Windows statistical package version 22 .

\section{Results}

\section{Subject Characteristics}

Subject characteristics are shown in Table 1. Sixty-four neonates from 23 to 40 weeks' gestation were enrolled in this study. They were stratified into three groups based on their gestational age: preterm $(n=21)$, late preterm $(n=$ $22)$, and term $(n=21)$, with gestational ages of $30.9 \pm 2.9$ weeks, $34.9 \pm 0.8$ weeks, and $39.1 \pm 1.1$ weeks, respectively. Their birthweights were 1,665 $\pm 538 \mathrm{~g}, 2,351 \pm 624 \mathrm{~g}$, and 3,379 $\pm 509 \mathrm{~g}$, respectively. Sex distribution between the groups was similar $(p=0.875)$, although more males $(n=40)$ than females $(n=24)(p=0.046)$ were enrolled in the study. The groups did not differ significantly with respect to mode of delivery, age of the mother, or Apgar scores at 1 or $5 \mathrm{~min}$. 


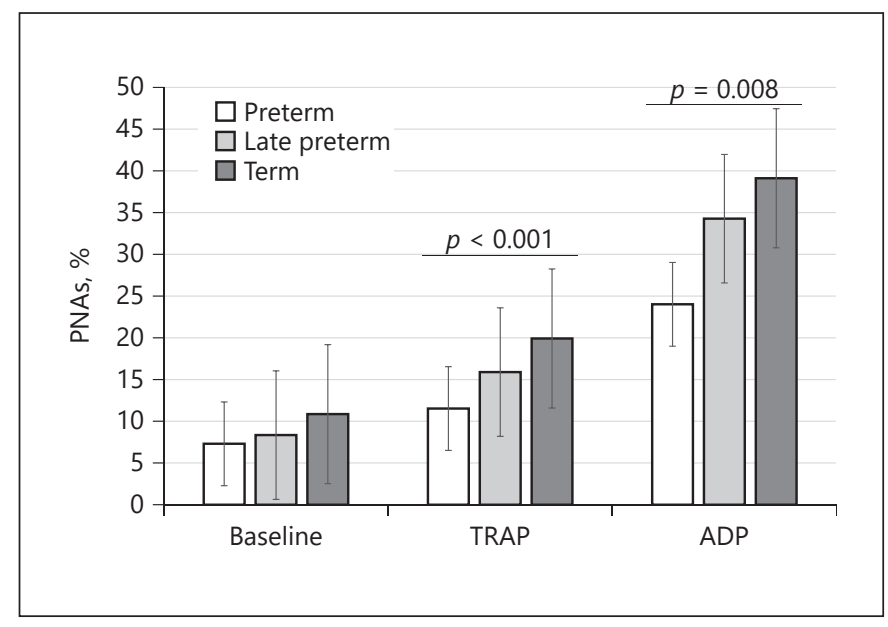

Fig. 2. Platelet-neutrophil aggregates (PNAs). Percentage of CD61 PerCP-positive neutrophils in the cord blood of preterm $(n=21)$, late preterm $(n=22)$, and term $(n=21)$ newborns. Results are given as mean \pm standard deviation and analysis is based on oneway ANOVA test and Bonferroni multiple comparison. The power for ANOVA analysis of PNAs after TRAP and ADP stimulations was 0.90 and 0.76 , respectively. ADP, adenosine $5^{\prime}$-diphosphate; PerCP, peridinin-chlorophyll-protein; TRAP, thrombin receptoractivating peptide.

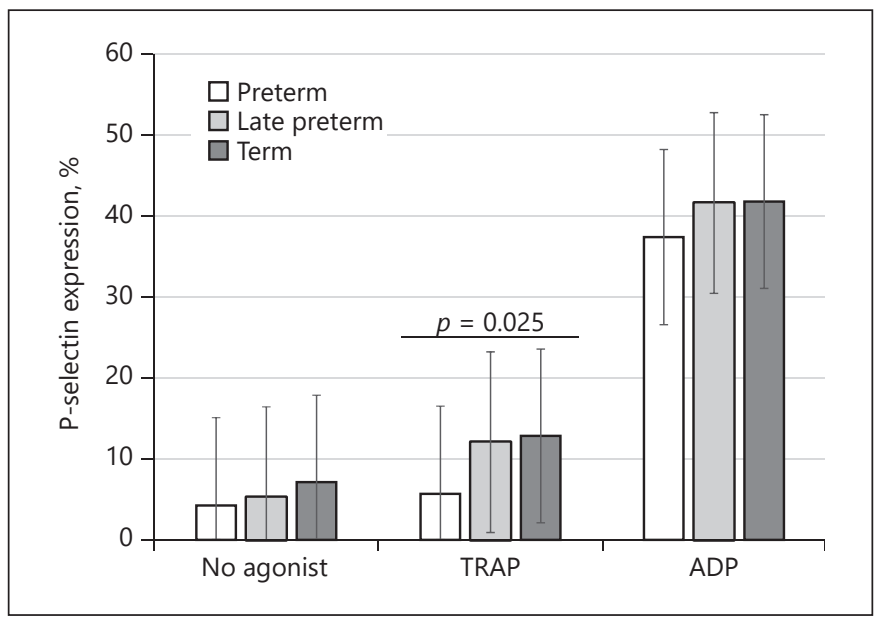

Fig. 3. The percentage of cord blood platelets expressing P-selectin in preterm $(n=21)$, late preterm $(n=22)$, and term $(n=21)$ newborns. Results are given as mean \pm standard deviation and analysis is based on one-way ANOVA after log transformation. The power was 0.48 for P-selectin expression after TRAP stimulation. ADP, adenosine $5^{\prime}$-diphosphate; TRAP, thrombin receptor-activating peptide.

Table 1. Subject characteristics

\begin{tabular}{|c|c|c|c|c|}
\hline & $\begin{array}{l}\text { Preterm } \\
(n=21)\end{array}$ & $\begin{array}{l}\text { Late preterm } \\
(n=22)\end{array}$ & $\begin{array}{l}\text { Term } \\
(n=21)\end{array}$ & $p$ value \\
\hline Birthweight, g & $1,665 \pm 538$ & $2,351 \pm 624$ & $3,379 \pm 509$ & $<0.001^{\mathrm{a}}$ \\
\hline Gestational age, weeks & $30.9 \pm 2.9$ & $34.9 \pm 0.8$ & $39.1 \pm 1.1$ & $<0.001^{\mathrm{a}}$ \\
\hline Maternal age, years & $29.3 \pm 7.5$ & $27.5 \pm 5.7$ & $30.9 \pm 7.2$ & $0.270^{\mathrm{a}}$ \\
\hline \multicolumn{5}{|l|}{ Sex } \\
\hline Male & $13(62 \%)$ & $13(59.1 \%)$ & $14(66.7 \%)$ & \multirow[t]{2}{*}{$0.875^{\mathrm{b}}$} \\
\hline Female & $8(38 \%)$ & $9(40.9 \%)$ & $7(33.3 \%)$ & \\
\hline \multicolumn{5}{|l|}{ Mode of delivery } \\
\hline Cesarean section & $13(62 \%)$ & $9(40.9 \%)$ & $14(66.7 \%)$ & \multirow[t]{2}{*}{$0.192^{\mathrm{b}}$} \\
\hline Vaginal delivery & $8(38 \%)$ & $13(59.1 \%)$ & $7(33.3 \%)$ & \\
\hline Apgar score at $1 \mathrm{~min}$ & $7(5-8)$ & $8(7-8)$ & $8(8-8)$ & $0.165^{\mathrm{c}}$ \\
\hline Apgar score at $5 \mathrm{~min}$ & $8(8-9)$ & $8(8-9)$ & $9(9-9)$ & $0.053^{\mathrm{c}}$ \\
\hline
\end{tabular}

Values are presented as mean \pm standard deviation, $n(\%)$, or median (interquartile range). ${ }^{\mathrm{a}}$ One-way ANOVA. ${ }^{\mathrm{b}}$ Pearson $\chi^{2}$ test. ${ }^{\mathrm{c}}$ Kruskal-Wallis test.

\section{Formation of PNAs}

Significant differences were observed between groups in the percentage of neutrophils associated with platelets (PNAs formed) in response to either TRAP- or ADP-mediated platelet activation. Bonferroni post hoc comparison revealed that percentage PNAs formed in preterm newborns, after TRAP or ADP stimulations, were significantly lower than in term neonates $(11.5 \pm 5.2 \%$ vs. 19.9 $\pm 9.1 \%, p<0.001$, or $24.0 \pm 10.1 \%$ vs. $39.1 \pm 18.2 \%, p=$ 0.008 , respectively) (Fig. 2). Neutrophils from cord blood of late preterm newborns were intermediate between preterm and term newborns $(15.9 \pm 5.0 \%$ or $34.3 \pm 10.0 \%$ 
Fig. 4. Pearson correlation of the log \% Pselectin-positive platelets with PNAs in the cord blood samples of 64 neonates during TRAP (a) (power $=0.98$ ) and $\mathrm{ADP}$ (b) (power $=0.99$ ) stimulation, respectively. ADP, adenosine $5^{\prime}$-diphosphate; PNA, platelet-neutrophil aggregate; TRAP, thrombin receptor-activating peptide.

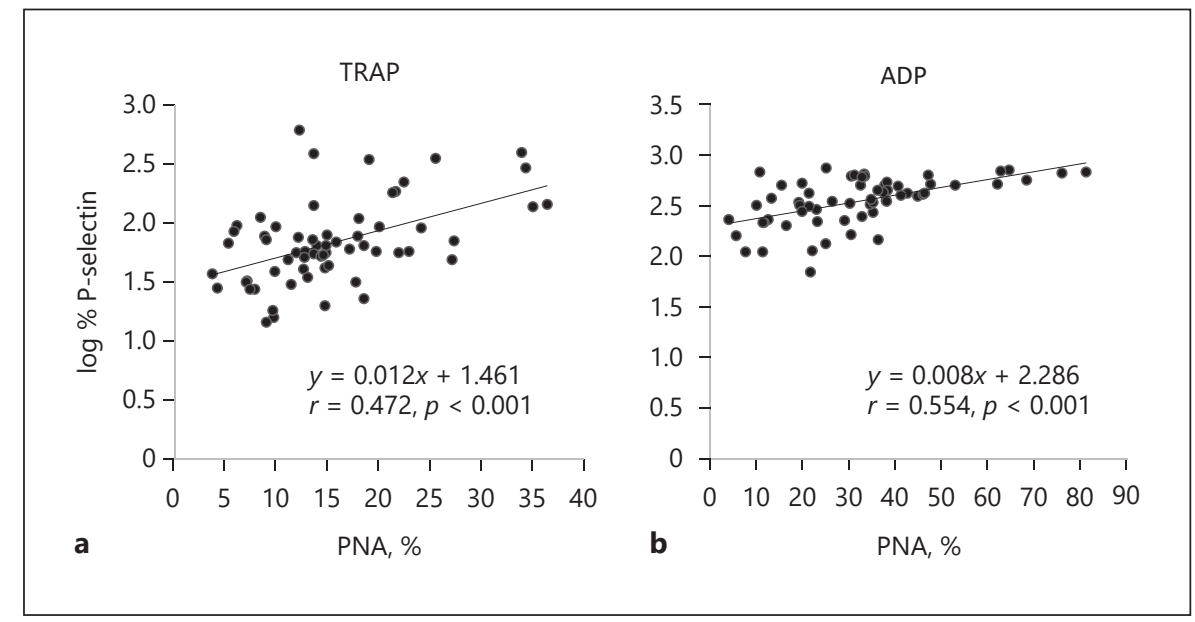

after TRAP- or ADP-mediated activation, respectively). No significant differences were observed between groups without platelet activation.

\section{Expression of P-Selectin}

The percentage of platelets expressing $\mathrm{P}$-selectin was analyzed for each of the groups. Log-transformed platelet $\mathrm{P}$-selectin expression was significantly lower in preterm $(5.7 \pm 3.7 \%)$ compared to late preterm $(12.1 \pm 15.1 \%)$ or term $(12.9 \pm 11.2 \%)$ neonates $(p=0.025)$ after stimulation with TRAP (Fig. 3). However, with current sample numbers the estimated power was 0.48 . Nevertheless, logtransformed percentages of P-selectin-positive platelets correlated with neutrophil interactions (PNAs), having Pearson's correlation coefficients of $r=0.472(p<0.001$, power $=0.98)$ and $0.554(p<0.001$, power $=0.99)$ following TRAP and ADP activations, respectively (Fig. 4).

\section{Discussion}

Premature neonates are at increased risk for hemorrhagic and inflammatory morbidities such as periventricularintraventricular hemorrhage, gastrointestinal bleeding, and sepsis. Platelets play an essential role as components of the hemostatic response to vascular breaches, limiting bleeding severity, particularly from the high-pressure arterial vessels. The developmental aspects of the hemostatic system, and especially platelet activation and functions in the newborn, remain to be fully characterized. The objective of this study was to evaluate the formation of PNAs and the expression of platelet $\mathrm{P}$-selectin in cord blood as a function of the newborn's gestational age at birth.

Lower Platelet-Neutrophil Aggregates in Preterm Neonates
Platelet-neutrophil interactions lead to physiological changes in platelets and neutrophils affecting their functions. Platelet aggregation and thromboxane release are enhanced by interactions with neutrophils, while neutrophils, in turn, utilize platelet-derived phospholipids for chemokine production $[29,33]$. In addition, this interaction promotes the recruitment of neutrophils to inflammatory tissues [34] and primes them for adhesion, phagocytosis, and killing [35]. Lower neutrophil functions were reported in newborns as a whole [36] and in preterm neonates in particular [37]. Less frequent interactions between platelets and neutrophils presented here (Fig. 2) may contribute to lower neutrophil function in preterm newborns and may partly explain the increased susceptibility to infections in this cohort [38]. Preterm newborns are known to be susceptible to infections in a way that is similar to that observed in adults with neutropenia [37]. Further studies are needed to explore the relevance of this interaction.

P-selectin is important for PNA formation and subsequent neutrophil function $[39,40]$. We observed positive correlations between PNA levels and expression of P-selectin (Fig. 4), consistent with earlier work focusing on adult platelet-leukocyte aggregates [41]. This is further supported by findings that platelet activation and P-selectin expression are needed for platelet-neutrophil complex formation [39].

$\mathrm{P}$-selectin is one of the most analyzed platelet activation markers $[42,43]$. It is released from platelet $\alpha$ granules during activation and is important in the interaction of platelets with leukocytes or vascular endothelium [44, 45]. The expression of platelet P-selectin in newborns was lowest in the preterm group, consistent with earlier stud- 
ies $[25,46]$. However, these lower values only reached significance when TRAP was the agonist (Fig. 3). Moreover, we observed increased variability in P-selectin levels in our study population, similar to that reported by other investigators $[17,23,46]$.

Platelet activation by TRAP resulted in marginal increases in P-selectin expression and PNA formation. This is consistent with other studies showing poor TRAP response of platelets at birth, due to low levels of the protease-activated receptors (PAR-1 and PAR-4) [47, 48]. Platelet responsiveness to TRAP was then observed to improve postnatally with age $[24,25,48]$.

There is a clear correlation between PNA formation and $\mathrm{P}$-selectin expression, regardless of the agonist used. Yet, it is of interest that the correlation of PNA expression with gestational age is stronger than that of $\mathrm{P}$-selectin expression. This implies that PNA formation is not solely dependent on platelets, but also requires functional developments of neutrophils, concordant with reported lower neutrophil functions in premature newborns [36].

The major findings of this study include (1) significantly lower levels of PNAs in preterm neonates, implying that the ability to form them increases with gestational age, (2) lower degranulation of platelet a granules as measured by expressed $\mathrm{P}$-selectin in preterm neonates in response to TRAP stimulation, and (3) significant positive correlations between P-selectin expression and PNA formation. Further studies are needed to examine the implication of these findings for newborn physiology and morbidity.

\section{Acknowledgments}

We are grateful to Dorothy Forde, Judy Gates, and Salma Kabir for their invaluable help in obtaining informed consents for this study. This work was supported in part by NIH grants R01 NR011209-08 and R25 GM060507.

\section{Statement of Ethics}

All procedures followed were in accordance with the ethical standards of the responsible committee on human experimentation (institutional and national) and with the Helsinki Declaration of 1975, as revised in 2008. Informed consent was obtained from the parents of all patients for their inclusion in the study.

\section{Disclosure Statement}

The authors declare that they have no conflict of interest.

\section{References}

1 Brewer DB. Max Schultze (1865), G. Bizzozero (1882) and the discovery of the platelet. $\mathrm{Br}$ J Haematol. 2006 May;133(3):251-8.

2 Vander Velden P, Giles AR. A detailed morphological evaluation of the evolution of the haemostatic plug in normal, factor VII and factor VIII deficient dogs. Br J Haematol. 1988 Nov; 70(3):345-55.

3 Vieira-de-Abreu A, Campbell RA, Weyrich AS, Zimmerman GA. Platelets: versatile effector cells in hemostasis, inflammation, and the immune continuum. Semin Immunopathol. 2012 Jan;34(1):5-30.

4 Italiano JE Jr, Richardson JL, Patel-Hett S, Battinelli E, Zaslavsky A, Short S, et al. Angiogenesis is regulated by a novel mechanism: pro- and antiangiogenic proteins are organized into separate platelet $\alpha$ granules and differentially released. Blood. 2008 Feb;111(3): 1227-33.

5 Cullinane AB, O'Callaghan P, McDermott K, Keohane C, Cleary PE. Effects of autologous platelet concentrate and serum on retinal wound healing in an animal model. Graefes Arch Clin Exp Ophthalmol. 2002 Jan;240(1): $35-41$.
6 Margolis DJ, Kantor J, Santanna J, Strom BL, Berlin JA. Effectiveness of platelet releasate for the treatment of diabetic neuropathic foot ulcers. Diabetes Care. 2001 Mar;24(3):483-8.

7 Youssefian T, Drouin A, Massé JM, Guichard J, Cramer EM. Host defense role of platelets: engulfment of HIV and Staphylococcus aureus occurs in a specific subcellular compartment and is enhanced by platelet activation. Blood. 2002 Jun;99(11):4021-9.

8 McMorran BJ, Marshall VM, de Graaf C, Drysdale KE, Shabbar M, Smyth GK, et al. Platelets kill intraerythrocytic malarial parasites and mediate survival to infection. Science. 2009 Feb;323(5915):797-800.

9 Leslie M. Cell biology. Beyond clotting: the powers of platelets. Science. 2010 Apr; 328(5978):562-4.

10 Palumbo JS, Talmage KE, Massari JV, La Jeunesse CM, Flick MJ, Kombrinck KW, et al. Platelets and fibrin(ogen) increase metastatic potential by impeding natural killer cell-mediated elimination of tumor cells. Blood. 2005 Jan;105(1):178-85.
11 Haley KM, Recht M, McCarty OJ. Neonatal platelets: mediators of primary hemostasis in the developing hemostatic system. Pediatr Res. 2014 Sep;76(3):230-7.

12 Andrew M, Castle V, Saigal S, Carter C, Kelton JG. Clinical impact of neonatal thrombocytopenia. J Pediatr. 1987 Mar;110(3):45764.

13 Elmoneim AA, Zolaly M, El-Moneim EA, Sultan E. Prognostic significance of early platelet count decline in preterm newborns. Indian J Crit Care Med. 2015 Aug;19(8):45661.

14 Baer VL, Lambert DK, Henry E, Christensen RD. Severe Thrombocytopenia in the NICU. Pediatrics. 2009 Dec;124(6):e1095-100.

15 Duppré P, Sauer H, Giannopoulou EZ, Gortner L, Nunold H, Wagenpfeil S, et al. Cellular and humoral coagulation profiles and occurrence of IVH in VLBW and ELWB infants. Early Hum Dev. 2015 Dec;91(12):695-700.

16 Yulandari I, Rundjan L, Kadim M, Amalia P, Wulandari HF, Handryastuti S. The relationship between thrombocytopenia and intraventricular hemorrhage in neonates with gestational age $<35$ weeks. Paediatr Indones. 2016;56(4):242-50. 
17 Frelinger AL 3rd, Grace RF, Gerrits AJ, Berny-Lang MA, Brown T, Carmichael SL, et al. Platelet function tests, independent of platelet count, are associated with bleeding severity in ITP. Blood. 2015 Aug;126(7):873-9.

18 Gatti L, Guarneri D, Caccamo ML, Gianotti GA, Marini A. Platelet activation in newborns detected by flow-cytometry. Biol Neonate. 1996;70(6):322-7.

19 Grosshaupt B, Muntean W, Sedlmayr P. Hyporeactivity of neonatal platelets is not caused by preactivation during birth. Eur J Pediatr. 1997 Dec;156(12):944-8.

20 Rajasekhar D, Barnard MR, Bednarek FJ, Michelson AD. Platelet hyporeactivity in very low birth weight neonates. Thromb Haemost. 1997 May;77(5):1002-7.

21 Strauss T, Levy-Shraga Y, Ravid B, SchushanEisen I, Maayan-Metzger A, Kuint J, et al. Clot formation of neonates tested by thromboelastography correlates with gestational age. Thromb Haemost. 2010 Feb;103(2):344-50.

22 Roschitz B, Sudi K, Köstenberger M, Muntean W. Shorter PFA-100 closure times in neonates than in adults: role of red cells, white cells, platelets and von Willebrand factor. Acta Paediatr. 2001 Jun;90(6):664-70.

23 Cade JF, Hirsh J, Martin M. Placental barrier to coagulation factors: its relevance to the coagulation defect at birth and to haemorrhage in the newborn. BMJ. 1969 May;2(5652):2813.

24 Pietrucha T, Wojciechowski T, Greger J, Jedrzejewska E, Nowak S, Chrul S, et al. Differentiated reactivity of whole blood neonatal platelets to various agonists. Platelets. 2001 Mar;12(2):99-107.

25 Sitaru AG, Holzhauer S, Speer CP, Singer D, Obergfell A, Walter U, et al. Neonatal platelets from cord blood and peripheral blood. Platelets. 2005 May-Jun;16(3-4):203-10.

26 Braun OO, Slotta JE, Menger MD, Erlinge D, Thorlacius H. Primary and secondary capture of platelets onto inflamed femoral artery endothelium is dependent on P-selectin and PSGL-1. Eur J Pharmacol. 2008 Sep;592(1-3) $128-32$.

27 Semple JW, Freedman J. Platelets and innate immunity. Cell Mol Life Sci. 2010 Feb;67(4): 499-511.
28 Kornerup KN, Salmon GP, Pitchford SC, Liu WL, Page CP. Circulating platelet-neutrophil complexes are important for subsequent neutrophil activation and migration. J Appl Physiol (1985). 2010 Sep;109(3):758-67.

29 Faint RW. Platelet-neutrophil interactions: their significance. Blood Rev. 1992 Jun;6(2): 83-91.

30 Lam FW, Burns AR, Smith CW, Rumbaut RE. Platelets enhance neutrophil transendothelial migration via $\mathrm{P}$-selectin glycoprotein ligand-1. Am J Physiol Heart Circ Physiol. 2011 Feb;300(2):H468-75.

31 Psaila B, Bussel JB, Frelinger AL, Babula B, Linden MD, Li Y, et al. Differences in platelet function in patients with acute myeloid leukemia and myelodysplasia compared to equally thrombocytopenic patients with immune thrombocytopenia. J Thromb Haemost. 2011 Nov;9(11):2302-10.

32 Nagasawa A, Matsuno K, Tamura S, Hayasaka K, Shimizu C, Moriyama T. The basis examination of leukocyte-platelet aggregates with CD45 gating as a novel platelet activation marker. Int J Lab Hematol. 2013 Oct;35(5): 534-41.

33 Faraday N, Scharpf RB, Dodd-o JM, Martinez EA, Rosenfeld BA, Dorman T. Leukocytes can enhance platelet-mediated aggregation and thromboxane release via interaction of $\mathrm{P}$-selectin glycoprotein ligand 1 with P-selectin. Anesthesiology. 2001 Jan;94(1):145-51.

34 Zarbock A, Polanowska-Grabowska RK, Ley K. Platelet-neutrophil-interactions: linking hemostasis and inflammation. Blood Rev. 2007 Mar;21(2):99-111.

35 Peters MJ, Dixon G, Kotowicz KT, Hatch DJ, Heyderman RS, Klein NJ. Circulating platelet-neutrophil complexes represent a subpopulation of activated neutrophils primed for adhesion, phagocytosis and intracellular killing. Br J Haematol. 1999 Aug;106(2):391-9.

36 Lipp P, Ruhnau J, Lange A, Vogelgesang A, Dressel A, Heckmann M. Less Neutrophil Extracellular Trap Formation in Term Newborns than in Adults. Neonatology. 2017; 111(2):182-8

37 Carr R. Neutrophil production and function in newborn infants. Br J Haematol. $2000 \mathrm{Jul}$; 110(1):18-28

38 Simonsen KA, Anderson-Berry AL, Delair SF, Davies HD. Early-onset neonatal sepsis. Clin Microbiol Rev. 2014 Jan;27(1):21-47.
39 Mauler M, Seyfert J, Haenel D, Seeba H, Guenther J, Stallmann D, et al. Platelet-neutrophil complex formation - a detailed in vitro analysis of murine and human blood samples. J Leukoc Biol. 2016 May;99(5):781-9.

40 Zuchtriegel G, Uhl B, Puhr-Westerheide D, Pörnbacher M, Lauber K, Krombach F, et al. Platelets Guide Leukocytes to Their Sites of Extravasation. PLoS Biol. 2016 May; 14(5): e1002459.

41 Irving PM, Macey MG, Shah U, Webb L, Langmead L, Rampton DS. Formation of platelet-leukocyte aggregates in inflammatory bowel disease. Inflamm Bowel Dis. 2004 Jul;10(4):361-72.

42 Martínez-Sánchez SM, Minguela A, PrietoMerino D, Zafrilla-Rentero MP, AbellánAlemán J, Montoro-García S. The Effect of Regular Intake of Dry-Cured Ham Rich in Bioactive Peptides on Inflammation, Platelet and Monocyte Activation Markers in $\mathrm{Hu}-$ mans. Nutrients. 2017 Mar;9(4):321.

43 Morel A, Rywaniak J, Bijak M, Miller E, Niwald M, Saluk J. Flow cytometric analysis reveals the high levels of platelet activation parameters in circulation of multiple sclerosis patients. Mol Cell Biochem. 2017 Jun;430(12):69-80.

44 Dole VS, Bergmeier W, Mitchell HA, Eichenberger SC, Wagner DD. Activated platelets induce Weibel-Palade-body secretion and leukocyte rolling in vivo: role of P-selectin. Blood. 2005 Oct;106(7):2334-9.

45 Vandendries ER, Furie BC, Furie B. Role of P-selectin and PSGL-1 in coagulation and thrombosis. Thromb Haemost. 2004 Sep; 92(3):459-66.

46 Wasiluk A, Mantur M, Szczepański M, Kemona H, Baran E, Kemona-Chetnik I. The effect of gestational age on platelet surface expression of CD62P in preterm newborns. Platelets. 2008 May; 19(3):236-8.

47 Schlagenhauf A, Schweintzger S, BirnerGrünberger R, Leschnik B, Muntean W. Comparative evaluation of PAR1, GPIb-IX$\mathrm{V}$, and integrin $\alpha \mathrm{IIb} \beta 3$ levels in cord and adult platelets. Hamostaseologie. 2010 Nov;30 Suppl 1:S164-7.

48 Schlagenhauf A, Schweintzger S, BirnerGruenberger R, Leschnik B, Muntean W. Newborn platelets: lower levels of proteaseactivated receptors cause hypoaggregability to thrombin. Platelets. 2010;21(8):641-7. 